\title{
The Impact of Media Convergence on Egyptian HR Practices: A Zoom on the Newsroom Post January 2011 Revolution
}

\author{
Tarek A. El Badawy ${ }^{1} \&$ Mariam M. Magdy ${ }^{1}$ \\ ${ }^{1}$ Faculty of Management Technology, German University in Cairo, Cairo, Egypt \\ Correspondence: Tarek A. El Badawy, Assistant Professor of Management, Department of Management and \\ Organization, Faculty of Management Technology, German University in Cairo, Cairo, Egypt. E-mail: \\ tarek.el-badawy@guc.edu.eg
}

Received: January 15, 2015

Accepted: January 27, 2015

Online Published: March 25, 2015

doi:10.5539/ibr.v8n4p10

URL: http://dx.doi.org/10.5539/ibr.v8n4p10

\begin{abstract}
Media convergence has proved to be a phenomenon that is here to stay. Employers and employees of media organizations are facing several challenges that come with the changing process. This study offers results from interviews conducted with employees from four media organizations in Egypt. Results show that post January 2011 revolution, media convergence has been on the rise as the result of social media's impact in influencing the political arena. Egyptian media organizations are going through incremental changes rather than radical ones. This causes confusion, frustration and inefficiency in the work of the media organizations. Human resource practitioners are facing changes in the recruitment, compensation and training methods of the newly multi-skilled journalists. Implications for managers and human resource practitioners along with recommendations and future research directions are provided.
\end{abstract}

Keywords: media convergence, human resources, January 2011 revolution, Egypt

\section{Introduction}

Media convergence is a phenomenon that is targeted by news organizations. Convergence is supported by technological evolutions that made connectivity and mobility the norm. On the social level, consumers have changed their habits as well, using the internet in searching for information, news and interacting with others (Boers, Ercan, Rinsdorf, \& Vaagan, 2012). This study introduces the results from interviews conducted on media convergence and its impact on the Egyptian Human resource (HR) practices inside the newsrooms of four Egyptian dailies. Studies on this topic in Egypt and Arab countries are considered rare. Converged multimedia newsrooms are very recent in Egypt, as the printed media market responded slowly to the increasing penetration of technology usage in Egypt in the last decade, alongside with the changes in Egyptian readers' consumption trends.

The Egyptian revolution in 25 January 2011 was a transformation point for this industry after the role of internet activism and social media has played in calling for this movement and reflecting the voice of the people. However, before the revolution, the Egyptian printed journalism has been suffering already from the decline of circulation and advertising revenues, while it was trying to find its way on the digital platforms, discovering the new potentials of this business area and what it takes to survive there. The concept of integrated newsrooms was still relatively new to the industry. While it started to get adopted in western countries after the millennium, it took few years to reach Egypt and be noticed by the players in the market. On the other hand, social media paved the road for change in Egypt.

As media digitization appears to be inevitable, traditional media is tending to be more compatible and cooperating with the new types and tools of communication, abandoning traditional ones that have always been working but started to fade away. The future is clearly digital; however, the consequences of these current changes on the industry in the future are hard to predict. New demands and requirements have to be met in order to cope with the digitization process. Those demands are related to the different levels of the supply chain in the industry including production, packaging and distribution. Newsrooms are the places where these adaptations take place, and journalists are the manpower that organizations depend on. Moving from single media to multimedia reporting requires a totally new structure of the newsroom and a creative usage of its resources.

Journalists as a main factor in journalism industry have been exposed to the winds of change, being introduced to 
new ways of working after long years of having same daily routines. They are expected to adopt new skills and being evaluated based on relatively new criteria. Multiskilling and multi-tasking are amongst the trends that are being more adopted in the newsrooms for reasons related to work efficiency and economics of the media. The increasing demands on journalists create a more pressured environment, which ultimately has a negative impact on journalistic standards (Cottle, 1999). Media convergence not only redefines the tasks of journalists and newsrooms, but also reshapes the business environments of media companies (Russ-Mohl, Nienstedt, \& Wilzcek, 2013).

The efforts of managers in media organizations to help journalists adapt to these changes have varied. While some of them have invested in training and development programs, others have left their journalists finding their way alone. The effect of the whole change on management's practices and consequently the journalists is the main focus of this study.

The main objective of this study is to explore the environment in Egyptian newsrooms following the changes imposed on them [newsrooms] post January 2011 revolution. Newsrooms started to take the digitization process as a phenomenon that is here to stay and consequently, the managers started making changes in the way of doing business, tools used, skills required and others. Journalists' responses on the change were also sought after from the interviews conducted for this study.

The structure of the paper will be as follows: the literature on media convergence, the transformations and challenges facing newsroom is discussed. Afterwards, a description of four Egyptian dailies, which were the focus of this study, is provided. This is followed by the methodology. The discussion section highlights the main changes happening inside the newsrooms including the convergence strategies adopted and the changes imposed on HR. Finally, concluding remarks are provided.

\section{Convergence and the Newsrooms}

Media organizations are facing, for years, the effects and consequences of media transformations and changes of consumption patterns that have directly affected the way they produce, monetize and plan. This phenomenon is referred to as media convergence. Convergence is a term that refers to "The ability of consumers to obtain multiple services on a single platform or device or obtain any given service on multiple platforms or devices" as per UK's convergent media regulator's definition (Ofcom, 2008), where "Convergence is all around us-mobile phones with video, radio and the Internet, radio over TV platforms and the Internet and TV over mobile platforms including digital radio, and the Internet-all facilitated by the move to digital technologies".

While convergence is widely thought as a mere technological process, it is not only that but also a profound and ongoing social, cultural and economic shift (Dwyer, 2010). Some common ideas referenced by the term include the flow of content across multiple media platforms, the cooperation between multiple media industries, the search for new structures of media financing that fall at the interstices between old and new media, and the migratory behavior of media audiences who would go almost anywhere in search of the kind of entertainment experiences they want.

More broadly, media convergence refers to a situation in which multiple media systems coexist and where media content flows fluidly across them. Convergence is understood here as an ongoing process or series of intersections between different media systems and not a fixed relationship (Jenkins, 2006). Briggs and Bourke (2002) reported that since the 1990s, the term 'convergence' has been applied most commonly to account for the development of digital technology, the integration of text, numbers, images and sound. At the level of everyday media production, distribution and consumption, significant global industry trends indicate profound shifts in the way audiences increasingly receive their daily media (Croteau \& Hoynes, 2006).

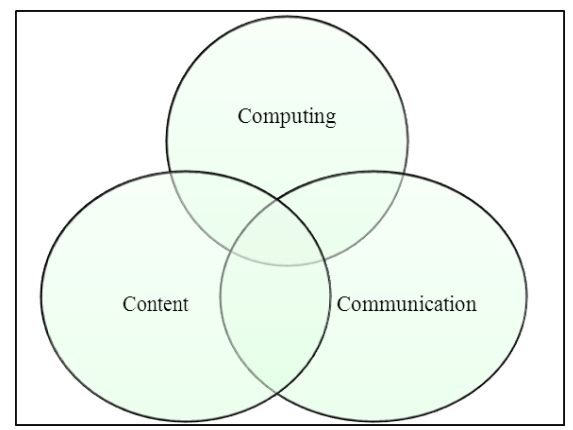

Figure 1. The three Cs of convergent media 
There are three overlapping circles that diagrammatically represent the three C's of convergent media (see figure 1). They involve Computing and information technology (IT), Communications networks, and digitized Content (Flew, 2008, p. 2). Convergent media uses Computing in creating Communication channels across different virtual platforms. This in turn frees the Content and allows it to spread across all platforms. On one hand, it makes news updated and readily available to everyone. On the other hand, it creates social and political challenges.

Journalism is facing several challenges. First, advertisers migrate to more flexible platforms like search engines and social networks which offer new opportunities for them to reach specific target groups more effectively and efficiently. Second, journalism's credibility is being challenged by Public Relations that is increasingly instrumentalizing journalism. Third, pay walls are not reaching a significant success, to compensate the fails in advertisements. As the public is unwilling to pay for online content, which may also result from journalism's increasing reliance on prefabricated PR feedings, and thus, the decreasing credibility is further supported (Russ-Mohl et al., 2013).

In addition, news organizations are big cost centers according to Turner (2011) with resources like printing houses, distribution centers and fleets and big numbers of fixed costs. Traditional producers are challenged by individuals who own nothing but a computer and a desk in their bedroom. Small independent start-ups are entering the market bringing fresh content, attractive layouts and causing readers to change their reading routines.

It was reported in May 2014 by the Egyptian Central Agency for Public Mobilization and Statistics that newspaper circulation in 2012 declined by $20 \%$ since 2011 . The number of newspaper copies distributed domestically and abroad has dropped as well, from 920.9 million to 646.6 million copies in 2012, a drop of about $30 \%$. News websites turned into a primary source of news to the Egyptian internet users who represent about $50 \%$ of the total population. Websites provide breaking news around the clock which made people abandon the print papers in favor of the digital platforms. At the same time, such digital outlets started to become a serious revenue source for newspapers that cannot be replaced anymore by the classic revenue sources, especially paper advertisements.

\section{Digitizing the Newsroom}

The main question that should be answered before starting the process of newsroom digitization is whether it is a mere digital alignment with the print workflow, or is it a new workflow that uses the print resources in a totally new context to empower this "new digital thing"?

To answer this question, the researchers looked into three factors anchored in the world of print that are shaping the "the innovation paths followed by online newsrooms trying to realize the web's interactive and multimedia capabilities" as per Boczkowski (2004). The three factors are:

a) The relationship with the print newsroom.

b) The definition of the editorial function.

c) The representation of the public.

Boczkowski explains that innovation in converted newsrooms should reflect the three factors. First, it should highlight the degree of openness and interaction between printed and online newsrooms. Second, it reflects whether contents are merely reproduced on digital platforms after printed media or there are alternative publications. Third, it should identify whether readers are considered consumers or producers and their degree of technological awareness. Surprisingly, the opposite of this applies on almost the four cases of this study, where the trials to create a new integrated/digitized newsroom have ended up mostly reproducing print's modes on the web. Senior editors in the four papers have admitted that $70-80 \%$ of the content that is published on the websites is produced by originally papers' journalists.

In order to digitize the workflow in the newsroom, newspapers have started in the last five years to adopt expensive digital (server based) workflow systems that allow them to control and monitor the content stream from all editors and to track changes that are applied to it through different work stages. In addition, the new workflow systems help shortening the production time of the paper version itself by linking the production process of the paper with the content flow that goes to the digital outlets of the paper. Adopting these new workflow systems takes months or maybe years in some cases to apply gradually, especially in the organizations that worked with paper based workflows originally before converting to the digital ones.

The effects of such developments of newsrooms and the working practices of journalists vary. Multiskilling, for instance, is a trend with increasing acceptance in news media, as journalists have to cope with a widening range of responsibilities in order to get their jobs done (Cottle, 1999). Multiskilling is a result of "management led economic decisions" as MacGregor (1997) suggests. On one hand, Multiskilling in newsrooms aims at cost 
reduction and efficiency improvement (Cottle, 1999). Multiskilling has brought some positive changes to newsrooms, such as more flexibility for journalists (MacGregor, 1997), the speeding up of a number of tasks such as data searching and making more information easily accessible to journalists (Leonard, 1992; Koch, 1991; Brooks, 1997), and the increased control by journalists over their own output (Wintour, 1989). On the other hand, technology brings "unsettling changes in working practices and routines", challenging "existing lines of demarcation in the journalistic workplace" as McNair (1998) suggests.

Bhuiyan (2009) believes that managers are the leaders of change. Once an organization adapts the convergent strategy, managers are responsible for steering the workforce towards the needed change. After the $25^{\text {th }}$ January 2011 revolution, convergence of media started to emerge and managers started facing challenges when it comes to introducing change, facilitating communication and encouraging teamwork. For human resource practitioners, they should rethink their strategy with regard to compensation, training and development. Multiskilling forces journalists to learn and practice new skills with training. Consequently, journalists are expecting better packages. Human resource practitioners and managers are responsible for changing the culture of the media organization and making it customer-focused rather than journalist-focused. Pressure to speed the postings of news and respond to changes in the political public opinion has never been up to its peak.

\section{Media Organizations' Profiles}

Four media organizations have been approached in this study. They are:

1) Al-Masry Al-Youm is an Egyptian privately owned daily newspaper that was first published in June 2004. It is published in Arabic and also maintains a companion website (almasryalyoum.com) which is also written in Arabic. An English version of the website was introduced in 2009 as the Al-masry Al-youm English Edition, which later evolved into Egypt Independent. It strives to be a full-service multimedia news organization for Egypt.

The paper is considered liberal, known for its' objectivity and sobriety. Despite its being funded by a group of Egyptian businessmen, it has not been known for its bias towards any of them. It is widely circulated all over Egypt and it mainly competes with Al-Ahram, the number one national paper in Egypt in regards of circulation. In 2014, the website of Al-masry Al-youm competed as one of the widest read news websites in Egypt. It was ranked $7^{\text {th }}$ on Alexa's ranking for Egyptian websites.

2) Al-Shorouk is an Egyptian privately owned daily newspaper. It was published in February 2009 in Arabic alongside with an online version (shorouknews.com). Al-Shorouk is known as a conservative liberal newspaper that is interested in both Egyptian and Arab affairs. It has been a credible source for news especially during the Egyptian revolution in 2011. It is also known with a big variety of Op-Eds written by prominent writers from Egypt and Arabic Countries, representing different ideological directions. These publications have led to different accusations for the paper to be supporting some political directions, specially the Muslim Brotherhood.

The website of Al-Shorouk has seen different ups and downs during the last few years as it was affected by the political bias' accusations. In addition, it was not being updated as much as other competitors' websites as a result of not adopting an integrated newsroom model by the paper till the moment. It is ranked today $110^{\text {th }}$ amongst Egyptian websites on Alexa.

3) Al-Watan is an Egyptian privately owned daily newspaper, first published in May 2012 in Arabic. The paper is liberal and is well known with its variety of content like sports, arts and women, as well as investigative reporting. One of the main competitive advantages of the paper is its website, which is known for video journalism, multimedia, interactivity, services and listings. The website is ranked $19^{\text {th }}$ in Alexa's ranking. Despite accusations to the paper that it is pro old regime in Egypt, it proved in a short time that it is a serious newspaper.

4) Al-Ahram is an Egyptian national daily newspaper, founded on 5 August 1875. It is the most widely circulating Egyptian daily newspaper. It has been considered as one of the most important sources of news regarding Egypt; however it has often been accused of being the voice of the Egyptian government.

In addition to the main edition published in Egypt, the paper publishes two other Arabic-language editions, one geared to the Arab World and the other aimed at an international audience, as well as editions in English and French.

Al-Ahram as an organization owns a wide portfolio of online websites and services that represents its many publications. The website of the daily paper (ahram.org.eg) is considered one of the first launched in Egypt. It is ranked $42^{\text {th }}$ on Alexa. However, the website reflects the content of the daily newspaper, while there is another portal for the up-to-date news from other sources. 


\section{Research Questions}

Based on the literature, the researchers concluded that to achieve the required change, a constructive and innovative workplace culture and supportive management are of utmost importance. At the same time, journalists are expected to be more flexible and versatile with change in the time their jobs are getting "rationalised and re-designated" (Cottle, 1999).

Hence, this study addressed three research questions:

1) Post January 2011 revolution, what changes were embedded in the media organization culture?

2) How did the job description of journalists change?

3) How was the journalistic credibility challenged?

\section{Method}

Semi-structured interviews were conducted with twenty journalists from the four Egyptian news organizations previously discussed. The sample included participants with different experiences and managerial levels for comparative reasons. All of them have experience with both paper and digital workflows and techniques to be able to answer questions about the difference between the two directions and the implications of this convergence on their careers.

\section{Results and Discussion}

\subsection{Convergence Strategies}

The participants from the four media organizations revealed that the management is clearly prone to use the existing potential of the organization with which "the greater the number of products and services that can be delivered to consumers via the same communications infrastructure, the better the economics of each service" (Doyle, 2002). The main focus is achieving economies of scale and scope. This requires not necessarily the reduction of cost but an efficient workflow. An efficient workflow in addition to reducing expenses and maximizing profit are the main pillars behind the ongoing efforts of the four organizations. Training employees to use digital workflow systems and reorganize workplaces are the only ways to achieve these objectives. However, the management, thinking on the short term only, does not put training as a top priority due to the price tag attached to it.

The interviews revealed that the four organizations have been adopting convergence strategies in different levels. Al-Masry Al-Youm and Al-Watan have already transformed their workflows. Both Al-Shorouk and Al-Ahram still have a combination of using paper and digital workflows, while both of them are planning to fully digitize the whole workflow soon, by integrating server based systems. Al-Watan was the only paper that started from the beginning with a digitized newsroom, while the rest of papers have initially started with semi digital systems and then started to digitize them at different stages of work.

While the workflow itself has been fully or partly digitized, the structure of the newsroom itself has not been changed a lot, except for adding some units to empower the work of the digital department, like social media, multimedia and video. There is also a separated desk unit for the website rather than the main desk unit for the paper, because most of the journalists are not trained enough yet to produce content mainly for digital platforms, so the unit of web desk is responsible mainly for converting the content to digital platforms, including the website, social media and SMS services. Such approach has a downside as journalists lose the ownership of their outputs. They mainly write and another individual converts and publishes. Some journalists did not favor the website units' method.

One drawback mentioned by the interviewees is that the convergence process is currently focused on digitizing the same old workflow almost to adapt it to the new digital media. There are no deep or fundamental changes for the whole mechanism to consider the different potentials and characteristics of both paper and digital media; except for rare examples like breaking news, that are being produced mainly for the digital outlets. The human resources of the four organizations are not present sufficiently to handle such issues related to handling grievances, accepting change and training to use the new tools. Post 2011 revolution, demand on printed media declined and consumers opt for fast and latest news on virtual platforms. Managers and HR practitioners should focus on fixing the process and training the people. Duplication and mere republishing of news should be minimized. Journalists should be introduced with clear job descriptions, ethical rules of practice and challenging rewards.

\subsection{Costs and Challenges of Transformation}

The research findings confirm that the cost of transformation to new forms of production and distribution is 
already an expensive and ongoing process. The cost here could be translated to several factors, including the cost of adopting new digital workflow systems, changing the culture of work by training and applying necessary changes to the workflow practices that are turning to be more flexible. Some challenges reported by the journalists were outdated and rigid organizational policies, fear of change, sensitive journalists' relationships and negative behavior often obstruct proper teamwork implementation in media newsrooms (Neuzil, Hansen, \& Ward, 1999).

Adopting new workflow systems seems to be simple relative to the needed changes in behaviors and development of skills and way of doing business. Care for training programs varies from an organization to another, while Al-Masry Al-Youm is the most developed organization in this part, the journalists mentioned that their organizations do not make the training courses mandatory. In most cases, training programs are not enough or covering all the developments in the industry. Journalists end up with the willingness and effort to develop themselves by self-learning and seek external training opportunities which adds burden on them.

Cost also affects the quality of the production. All interviewees have agreed that there is an increasing obsession of publishing news before competitors. While they have rejected the idea that this should come on the expense of credibility and fact checking, they have agreed that hasty publishing affects negatively the details and backgrounds that should come with the story "We publish first, details come later" as one of the editors has stated.

Press ethics are unidentified in Egypt. There are no laws or code of conduct that guide journalists in their writings. Moreover, the convergence of media has given journalists more space to search and publish news without sufficient scrutiny making journalists' credibility questioned. As Blach-Orsten and Burkal (2014) discuss, source, medium and the relationship between credibility and press ethics are three areas of research focus. Applying these areas on the four organizations puts Egyptian journalists' credibility at risk. The political situation and the demands of consumers have put journalists under pressure to bring the latest news in high speed and share it across all digital platforms to create the maximum impact. Journalists confessed that they get news and spread it without sufficiently checking its source and truthfulness. They use the digital platforms to create the needed vibe. With no code of ethics, they are not put under legal investigations and every journalist is left to his/her own conscience.

\subsection{Human Resources Challenges}

Multiple skills are considered essential for the success of all media employees (Boers et al., 2012). However, in all the newsrooms visited, multiskilling is still considered as an advantage recognized only by the journalist and not more than that. Visited newsrooms are still depending mainly on single skilled professionals in the different specializations, like multimedia, video, photography and social media. For a normal journalist to be able to do several tasks in parallel is an extra ability that he/she will not necessarily be rewarded for or be considered for a future promotion or raise.

Resistance to change is another common challenge amongst journalists in the new newsrooms. They justified it as trying to change a working routine that has not been changed for years is difficult. In addition, the media organizations do not offer motivational returns for the change. The journalists are left with insufficient compensation, and denied incentives. Inability to use technology was another reason. They are not aware of how to use technology tools and not willing to start learning from scratch. Howver, Al-Masry Al-Youm uses cash incentives for departments that achieve a pre-set quota of news as a technique to encourage journalists to engage more with the new system. Technology has come with advantages that cannot be totally ignored by journalists. For instance, their work has more chances to get published compared to previous times, because of the flexible space of internet, which strengthens their relationship with their sources. Finding sources, information and stories to cover became much easier than before by dint of search engines, social networks and other available communication tools.

Referring to the challenges that have been there while trying to adopt the new workflow, a senior editor at Al-Masry Al-Youm pointed out:

"Our main challenge was to change a stable culture of work, despite that most employees are young. Some journalists resisting change for many reasons including not being aware of the effects of development on the journalist himself, also being used to a way of working for years and not being keen to learn new things were all obstacles that we needed to cross. This took a time to be done, but we did it at the end".

Integration has helped to melt the ice between the originally paper journalists and the newcomers, the digital ones. For years in Egypt, digital editors have been considered as a lower level of journalists compared to paper journalists who were the more prestigious and credible. While readers do not really differentiate between both types of journalists, this idea has started to change inside the news organizations in Egypt. Most of interviewees have denoted that organizations do not discriminate between the two types of journalists in a systematic way, while 
some journalists still appreciate the idea of having their names on a printed paper more than a website. "There is still a culture amongst journalists of appreciation to the paper journalist comparing to the digital one, although internet is now wider and reaches way more readers comparing to paper" a web editor said.

One of the main obstacles in the integration process between paper and digital is communication. There are no official communication policies amongst different departments or written job descriptions for most of journalists. This leads to some work duplication and intersections that cost additional time and effort. In addition, this causes employees to be frustrated and confused.

\subsection{Time Pressure and Workload}

While all interviewed journalists in this study have agreed that technology tools are making lots of tasks easier and possible, most of them have claimed that the same technology adds pressure on them. While technology allows journalists to find data, information and resources quicker and easier, the quick pace of instant publishing on digital platforms all over the day has created a new kind workload that journalists have not experienced before being introduced to new digital tools.

An editor in Al-Watan comments on this saying: "The pressure that technology adds on us as journalists is big, while it can be minimized by experience and training, it also pushes us to set our publishing priorities better than before, to be able to follow up the pace of news".

Time pressure, production speed and competition have led to a less relaxed working environment for journalists. Sharing the same tools and work mechanisms amongst different newspapers, makes the competition way harder, and a big portion of this load reflects on journalists in their daily work.

One of the main concerns regarding the time pressure and increasing workloads is that news analysis becomes more difficult (Scott, 2005; Cottle, 1999; Tuchman, 1978; Altheide, 1976; and Epstein, 1973 as cited in Konstantinos \& Roger, 2008). Journalists are expected to be both fast and multitasking, making it more difficult for them to produce content with the same degree of details and analysis as they have used to do before.

Most of interviewees have also acknowledged the fact that being multi-skilled takes more time to finish tasks because of handling different elements in every piece of work, compared to leaving the extra elements like photo editing and data entry to specialized colleagues to handle them after writing the piece of work. However, there is a general agreement that the content production has become faster and that time that is spent on doing extra tasks is not delaying the workflow in a harmful way.

Regarding the research questions, it was concluded that convergence requires media organizations to adopt a culture of continuous change. Human resource practitioners are required to focus on introducing communication channels between employees, providing sufficient training for journalists to acquire new skills and drafting lucrative compensation packages to motivate and retain journalists. Regarding the job descriptions, media organizations still fail to provide clear and inclusive ones making journalists frustrated and unable to feel committed to their outputs. Finally, the credibility of journalists is challenged. With no code of ethics and high demand on new news, it is still early to draw conclusions on how this issue will develop and be resolved.

This study has several limitations. First, the sample size is small. Future studies should focus on enlarging and diversifying the sample to validate the results of this study. Second, it is suggested to focus on the human resources departments to get their insights on the transition phase in media organizations and compare them with the journalists' perceptions. Third, it is also suggested to shed light on the changes happening in recruitment, training and retention of journalists in media organizations.

\section{Conclusion}

The four organizations approached in this study revealed that there are radical changes taking place inside them as a result of media convergence accompanied by the political uprisings taking place since 2011 revolution. These changes are related to the way of doing work, the roles of journalists and the work environment.

As the tolerance with lack of digital skills decreases, the entry requirements for the newsrooms are getting more demanding for journalists who have to seek opportunities to learn about the basic tools and concepts of digital media to be able to get new jobs or to keep the current ones. Being a multi-skilled journalist is going to be a minimum requirement in the near future.

Egyptian newspapers are seeking new talents amongst their journalists, or hiring new ones, including readiness and the ability to deliver valuable content in different formats for both print and digital platforms. At the same time organizations are investing in the technological infrastructure, adopting digital workflow systems and developing their digital products to remain competitive. 
While the current efforts in Egypt seem to be as putting print media in a digital context rather than digitizing it from the core, it is a necessary step towards exploring new formats of content and workflows that are developed by native digital journalists and managers. There is still a long way of learning for both organizations and journalists to achieve that.

Employees in media organizations are facing several challenges. Resistance to change is happening as a normal reaction by a percentage of journalists who fear the change and its consequences on their stable jobs. Organizations and management need to adopt different techniques to handle such a resistance, whether by putting clear deadlines for journalists to adopt the new requirements and cope with them, or through different kinds of incentives to encourage journalists to work harder to get developed.

Pressured environment for journalists is a reality that is hard to ignore or avoid in such a transformational time. Organizations should exert more effort to avoid the possible impacts of pressure on the quality of the content rather than focusing mainly on quantity and speed of publishing. Further professional standards and workload management are required.

As the workflow and the structure of the newsroom are getting more complicated by the time, there is also a need to enhance communication policies in the newsroom; part of this is related to proper job analysis and providing clear job descriptions and responsibilities in the organization. The time has come to integrate better human resource management practices in the media organizations in Egypt.

In the same context, it is clear that media organizations need to invest more in career development programs to help journalists acquire the desired skills and abilities required in the digitization process. There is a clear need also to standardize the job specifications to be able to properly evaluate current employees and possible job candidates. On the other hand, media organizations should also focus on the top managerial level and start hiring managers who believe in convergence and how to introduce and manage it.

Bhuiyan (2009) provides some recommendations for managers introducing convergence in media organizations. First, training should be provided for both, managers and employees to ensure that they have the needed skills and minimize any discomfort or frustration. Second, planning the change is important to anticipate problems, commit adequate resources and follow the best methods in implementing the transition. Third, ongoing communication is important to answer questions, minimize confusion and build a positive new culture.

Boers et al. (2012) believe that even the teaching of journalism needs radical changes. Students should receive education and training on innovation, communication and multi-skilling.

\section{References}

Bhuiyan, S. I. (2009). Strategies for developing media managers for convergence: An analysis of perspectives from management theory and practice for managers of converged newsrooms. Pranjana: The Journal of Management Awareness, 12(2), 1-15.

Blach-Orsten, M., \& Burkal, R. (2014). Credibilty and the media as a political institution. Nordicom Review, 35, Special Issue, 67-79.

Boczkowski, P. (2004). The processes of adopting multimedia and interactivity in three online newsrooms. Journal of Communication, 54, 197-213. http://dx.doi.org/10.1111/j.1460-2466.2004.tb02624.x

Boers, R., Ercan, E., Rinsdorf, L., \& Vaagan, R. W. (2012). From convergence to connectivism: Teaching journalism 2.0. Online Journal of Communication and Media Technologies, 2(4), 52-64.

Briggs, A., \& Burke, P. (2002). A social history of the media: From Gutenberg to the internet. Padstow, UK: Polity.

Brooks, B. S. (1997). Journalism in the information age. Boston, MA: Allyn and Bacon.

Cottle, S. (1999). From BBC newsroom to BBC newscentre: On changing technology and journalist practices. Convergence: Journal of New Information and Communication Technologies, 5(3), 22-43.

Croteau, D., \& Hoynes, W. (2007). The media industry: Structure, strategy and debates. Sage Publications. Retrieved

from http://www.sagepub.com/mcquail6/Online\%20readings/9b\%20Croteau\%20\&\%20Hoynes\%20-Devereux-C h-02.pdf

Doyle, G. (2002). Media ownership: The economics and politics of convergence and concentration in the UK and European media. SAGE.

Dwyer, T. (2010). Media Convergence. McGraw-Hill Education. 
Flew, T. (2008). New media: An introduction. Melbourne: Oxford University Press.

Jenkins, H. (2006). Welcome to convergence culture. Retrieved from http://henryjenkins.org/2006/06/welcome_to_convergence_culture.html

Koch, T. (1991). Journalism for the 21st century: Online information, electronic databases, and the news. New York: Greenwood Press.

Konstantinos, S., \& Roger, D. (2008). Inside the changing newsroom: Journalists' responses to media convergence. Aslib Proceedings, 60(3), 216-228. http://dx.doi.org/10.1108/00012530810879097

Leonard, T. (1992). Databases in the newsroom: Computer-assisted reporting. Online, 16(3), 62-65.

MacGregor, B. (1997) Multiskilling or deskilling? Visions of the future and realities of today. Live, Direct and Biased? Making Television News in the Satellite Age. London: Arnold.

McNair, B. (1998). The sociology of journalism. Bloomsbury Academic.

Neuzil, M., Hansen, K., \& Ward, J. (1999). Twin cities journalists' assessment of topic teams. Newspaper Research Journal, 20(1), 2-16.

Ofcom. (2008). The international communications market 2008. London: Ofcom.

Russ-Mohl, S., Nienstedt, H., \& Wilzcek, B. (2013). Journalism and media convergence. Berlin: Walter de Gruyter \& Co. http://dx.doi.org/10.1515/9783110302899

Scott, B. (2005). A contemporary history of digital journalism. Television New Media, 6(1), 89-126. http://dx.doi.org/10.1177/1527476403255824

Turner, S. (2011). How advertising changes in the digital revolution and how this affects news media. Unpublished manuscript for the conference "Media Convergence \& Journalism", University of Mainz.

Wintour, C. (1989). The rise and fall of Fleet Street. London: Hutchinson.

\section{Copyrights}

Copyright for this article is retained by the author(s), with first publication rights granted to the journal.

This is an open-access article distributed under the terms and conditions of the Creative Commons Attribution license (http://creativecommons.org/licenses/by/3.0/). 